\title{
The effect of tidal exchange on residence time in a coastal embayment
}

\author{
Patrick Rynne ${ }^{1}$, Ad Reniers $^{2}$, Jacobus van de Kreeke ${ }^{1}$, Jamie MacMahan ${ }^{3}$ \\ ${ }^{1}$ Rosenstiel School of Marine and Atmospheric Science \\ 4600 Rickebacker Causeway, Miami, FL, 33149, USA \\ ${ }^{2}$ Delft University of Technology \\ Meke/weg 5, 2628 CD Delft, Netherlands \\ ${ }^{3}$ Naval Postgraduate School \\ 1 University Circle, Monterey, Ca, 93943, USA
}

\section{Corresponding Author}

\author{
Patrick Rynne \\ Email: patrickrynne@gmail.com \\ Phone: +1 6175298165 \\ 4600 Rickenbacker Causeway, Miami FL, 33149
}

Abstract 
Numerical simulations of an idealized lagoon that is connected to the ocean via a tidal inlet show that the mean residence time is inversely proportional to tidal exchange. In the Delft3D model the tidal exchange is controlled by varying the inlet length, width and depth. These changes in the inlet geometry affect the tidal prism and the ebb/flood flow structure, which are shown to control the exchange of lagoon water with seawater. To map residence time within the lagoon, a new method that implements dye tracer is developed and shows that the tidally averaged residence time exhibits significant spatial variability. For inlet systems in which, as a first approximation, the lagoon can be described by a uniformly fluctuating water level, a simple transport model is developed to elucidate the specific processes that control tidal exchange and their effect on residence time. In this transport model tidal exchange is decomposed into two fractions, an ocean exchange fraction and a lagoon exchange fraction. It is shown that both fractions need to be included to better describe tidal exchange. Specifically, inclusion of a lagoon exchange fraction improves previous tidal prism models that assume complete mixing in the lagoon. The assumption of complete mixing results in an under-prediction of residence time. Relating the spatially averaged residence time results to the exchange fractions for each inlet geometry show that the residence time is inversely proportional to the product of the tidal exchange fractions. For these single inlet systems, Keulegan's 0-D hydrodynamic model shows good agreement with Delft3D in predicting the tidal prism, maximum flow velocity, and exchange fractions. With these parameters, estimates of the mean residence time can be reached through a relationship derived from the simple transport model. 


\section{Introduction}

Tidal inlets serve an important role in the hydrodynamics of the nearshore environment, as they are a conduit between the ocean and an embayment such as an estuary, harbor, or lagoon. Besides their logistical importance as our gateway to the sea, these regions also provide critical habitat for wildlife and sustain ecological diversity (Frey and Basan 1985; Mitsch and Gosselink 1993). How long water resides in an embayment can influence how chemical and biological processes affect its properties (Anderson et al 2003, Lee et al 2011). Residence time is determined by tidal exchange (Stommel and Farmer 1952, Dean and Taylor 1972, Fischer et al 1979). Missing from the literature is a physical relationship between the two. To define this relationship, new methods that quantify tidal exchange and residence time in an inlet system are presented.

The advent of numerical models allows for a robust quantification of residence time using tracers and drogues (Banas and Hickey 2005; Wijeratne and Rydberg 2007). The concepts of Bolin and Rodhe (1972) van de Kreeke (1983) are employed to calculate tidally-averaged residence time distributions in a lagoon. These computationally expensive calculations are then used to develop a simple transport model following Stommel and Farmer (1952). Based on the asymmetry of the ebb and flood flow patterns at the ocean side of the inlet, they quantified tidal exchange with a single fraction herein referred to as the ocean exchange fraction. This approach is supplemented by introducing a second exchange fraction, the lagoon exchange fraction that describes the partial mixing of ocean water with lagoon water within the lagoon. The product of these two fractions provides a better estimate of tidal exchange. The 
simple transport model relates the spatially averaged residence time in the lagoon with the product of the two exchange fractions, thereby providing a quick assessment of mean lagoon residence time. These methods are applied to various inlet geometries to determine how the inlet width, length and depth influence tidal exchange and residence time.

\section{Methods}

\subsection{Residence Time}

Residence time $\left(T_{r}\right)$ is commonly defined as the tidally-averaged time that a Lagrangian particle remains entrained within an embayment (Fischer et al 1979; van de Kreeke 1983; Orfila et al 2005; Wijeratne and Rydberg 2007). Similarly, a water parcel's age represents how long it has been entrained at any specific time (Fig. 1a). When compared to a simple population model as done by Bolin \& Rodhe (1972), water entering the domain is equivalent to the birth of an individual, and the age when that individual expires is equivalent to the residence time, the total time it spent in the domain. At any given time, the total population consists of various individuals of different ages and a flux of individuals coming into (originating within) and leaving (expiring from) the system. This definition, although simple in form is difficult in practice due to the challenges associated with physically tracking water parcels. As such, only approximations of residence times that employ natural tracers are feasible in the field (Mudge, 2008). Other measures to quantify the renewal of lagoon water are age (Arega and Badr, 2010), exposure time (Brauwere et al, 2011; Delhez, 2013), turnover time 
(Prandle, 1984; Ridderinkhof et al, 1990; Arneborg, 2004), and flushing time (Zimmerman, 1976; Monsen 2002).

To estimate the residence time, a neutrally buoyant Lagrangian particle is typically tracked from the moment it enters the domain to the moment it exits. Specifically, if it is released at time $t=t_{0}$ from a point defined by the Cartesian coordinates $\left(x_{0}, y_{0}, z_{0}\right)$, the residence time for that location and release time is defined as $T_{r}\left(x_{0}, y_{0}, z_{0}, t_{0}\right)$ (Fig. 1a). Bolin and Rodhe (1972) and van de Kreeke (1983) show that a fluid tracer (dye) can be used to calculate a tidally-averaged residence time. If dye is released continuously from a point until a tidally-averaged equilibrium is reached, the residence time for that release location is,

$$
\bar{T}_{r}\left(x_{0}, y_{0}, z_{0}\right)=\frac{M}{Q_{i n}},
$$

where $\bar{T}_{r}$ is the tidally averaged residence time, $M$ is the mass of dye in the system averaged over a tidal cycle and $Q_{i n}$ is the mass flow rate at which dye is released. How this approach is applied to Delft3D is presented in Section 2.3.

\subsection{Model Geometry}

The flow in tidal inlets is primarily driven by water level difference between the ocean and the lagoon (Keulegan 1951). The hydraulic classification of tidal inlets has been based on the ratio of the basin tidal amplitude and ocean tidal amplitude (Kjerfve 1986), which in turn can be determined using the Keulegan repletion coefficient $K_{1}$ 
(Keulegan, 1967). Seabergh (2008) presents a thorough summary of the classification by Jarrett (1975) using $K_{1}$. Various definitions of embayments, such as for estuaries, lagoons, river mouths, bays, and fjords, have been utilized in the literature (Dyer 1973, Kjerfve 1994). Here, the inland body of water that connects to a tidal inlet is referred to as a 'back barrier lagoon' (Fig. 1b). The methods used in the Delft3D modeling presented here are applicable to any embayment that connects to the sea through a restricted channel including the inlets of Florida, the fjords in Scandinavia and Chile, the rias of Spain, the voes and sea-lochs of Scotland, and the loughs of Ireland (Gillibrand et a/2013).

To form an appropriate idealized domain, the empirical relationship between the tidal prism $(P)$ and cross-sectional area $(A)$ for inlets at equilibrium in the natural environment is used (O'Brien, 1931).

$$
A=a P^{m}
$$

Here $a$ and $m$ are dimensionless coefficients. Powell et al (2006) applied this relationship to 67 ocean entrances along Florida's east and west coasts. For each entrance, the tidal amplitude, wave energy flux, grain size, mean depth, cross sectional area, tidal prism, ebb delta volume and flood delta volume was presented. We have supplemented this data set with inlet length and width estimates of each entrance using Google Earth. To determine a baseline inlet geometry from these observations, Eq. 2 is applied to entrances classified as inlets, resulting in $a=1.52 \times 10^{-6}$ and $m=1.22$. The mean tidal prism from these inlets $\left(1.5 \times 10^{7} \mathrm{~m}^{3}\right)$ is then applied to the relationship, 
resulting in a flow area of $865 \mathrm{~m}^{2}$. When combined with the mean inlet length $(1300 \mathrm{~m})$ and width (188m) measurements from Google Earth, a representative geometry is obtained. The depth of the basin is assumed to be the same as the depth in the inlet channel $(4.6 \mathrm{~m})$ for simplicity. From this baseline geometry, various inlet shapes are considered with varying length, width and depth. Further discussion on the model scenarios is found in Section 2.6 and a summary of the inlet dimensions studied is presented in Table 1. Next the principal semidiurnal tidal constituent (M2) amplitude of 0.5 meters is used as the offshore boundary condition. This magnitude is chosen as the approximate representative condition based on work at New River Inlet, NC (MacMahan, 2014). With the assumption of a uniformly fluctuating basin water level, the surface area of the lagoon is set to $1.5 \times 10^{7} \mathrm{~m}^{2}$ to achieve the desired tidal prism. When applied to a square geometry, this produces a lagoon that measures approximately $4 \mathrm{~km}$ in length and width. Together with the mean basin depth this results in a lagoon volume of $6.9 \times 10^{7} \mathrm{~m}^{3}$.

The tidal prism, the ratio of the lagoon tidal amplitude $\left(a_{b}\right)$ to the ocean tidal amplitude $\left(a_{o}\right)$, the peak flood velocity $\left(\hat{U}_{\text {flood }}\right)$ and the peak ebb velocity $\left(\hat{U}_{e b b}\right)$ are determined for each inlet geometry using Delft3D. The prism is determined from a time series of the cumulative flux of water through a cross section at the inlet mouth. Once the model has initiated, the tidal prism can be calculated as the volume of water that enters the system during a flood or leaves during an ebb. For an M2 tide, both are equal. This approach includes the water that fills and empties the inlet channel. The tidal amplitude ratio is obtained from water level time series at the center of the lagoon and offshore. The flood and ebb velocity are obtained from the center of the inlet 
channel. The tidal prism can also be obtained by multiplying the tidal range in the basin by its' surface area. This approach results in tidal prisms that are on average $5 \%$ different than the cumulative flux method. The difference is attributed to the fact that the tidal range is not uniform everywhere in the basin and inlet.

\subsection{Model setup}

The flow module of Delft3D is used to simulate the hydrodynamics of idealized tidal inlet systems. Various site-specific modeling studies can be found in the literature, e.g. Wang et al 1995, Cayocca 2001, Elias et al 2012, that demonstrate the ability of numerical models to accurately represent natural inlet systems. Delft3D can be operated in a depth-averaged mode or a three dimensional mode with varying vertical layer thicknesses. A depth-averaged calculation was chosen because of the significant computational cost of running a residence time simulation in 3D. The depth-averaged calculations incorporate the non-linear shallow water equations for the fluid motion and the depth-averaged advection-diffusion equations for the transport. Advective and dissipative terms are balanced by Coriolis, horizontal pressure terms that are derived from Boussinesq approximations, horizontal Reynolds' stresses, and external sources and sinks of momentum such as discharges or withdrawals of water. We direct the reader to Lesser et al (2004) for a detailed description of the model and equations.

The horizontal grid resolution is coarsest offshore $(\sim 100 \mathrm{~m})$ and finest in the inlet $(\sim 30 \mathrm{~m})$ (Fig. 1b). The model is forced by a seaward M2 water-level boundary offshore and two lateral Neumann boundaries (Lesser et al. 2004). The model is run with a time step of 0.5 minutes. A uniform Manning bottom roughness coefficient of $n=0.028$ and a 
free slip condition are imposed (Mehta and Özsöy 1978, Elias et al 2012). Sub-grid scale turbulence is estimated with a Horizontal Large Eddy Simulation (HLES) approximation using a high-pass filter operation (Uittenbogaard, 1998). This approach in combination with a small background eddy viscosity $\left(v_{h}=10^{-5} \mathrm{~m}^{2} / \mathrm{s}\right)$ was used successfully to describe the turbulent mixing of dye in a natural river flow (Swick et al., 2014). The corresponding diffusivity $\left(D_{h}=10^{-4} \mathrm{~m}^{2} / \mathrm{s}\right)$ is obtained by dividing the turbulent eddy viscosity by the Prandtl-Schmidt number of 0.7 .

To produce residence time distributions following Eq. 1, the domain is populated with 99 dye sources distributed equally across the two-dimensional grid of the lagoon. This is the maximum number of unique constituents that the model can execute simultaneously. The same procedure can also be applied to a three-dimensional grid. An example of the output curves from the model and an explanation of the procedure to calculate residence time from them are presented in Appendix A. Each source releases $10^{-6}$ cubic meters per second of a unique fluid tracer. This allows the distribution of dye from each source to be tracked independently. Once the system reaches a tidallyaveraged equilibrium, the transport of each constituent out of the system through the inlet mouth is balanced by the flux introduced at each source. When this condition is met, the tidally-averaged residence time for each source location is calculated using Eq. 1 and combined to produce a distribution. The mean residence time for the lagoon is obtained by spatially averaging the distribution. This approach is applied to each inlet geometry and the results are presented in Table 2.

\subsection{Tidal Exchange Fractions}


Stommel and Farmer (1952) first presented a conceptual model that describes how asymmetry in ebb and flood flow patterns on the ocean side of an inlet creates tidal exchange (Fig. 1C). Ebb flows exit the inlet into the ocean as a narrow and energetic jet while flood flows are drawn into the inlet from the ocean radially. Other approaches have expanded on this idea by implementing particle tracking in numerical models to quantify exchange fractions. Awaji et al (1980) tracked the movement of particles over an entire tidal cycle in a simple basin and found that $87 \%$ of the tidal prism was renewed. Ridderinkhof et al (1990) applied the same approach to a model of tidal basins that are connected to the Dutch Wadden Sea through four inlets and calculated a mean exchange ratio of $11.3 \%$. Other efforts have taken an observation-based approach, utilizing natural tracers in the field to approximate exchange. Pritchard (1960) uses salt balance to estimate ocean exchange in Chincoteague Bay to be approximately 34\%. Parker et al (1972) use chlorides as tracers in San Francisco Bay and found an exchange of approximately 24\%. Chadwick and Largier (1999) utilize a naturally occurring ultraviolet fluorescence tracer in San Diego Bay to calculate an exchange of approximately $55 \%$. These approaches do not take into account how each ebb and flood tide is influenced by the previous tidal cycle and therefore only partially describe the process of tidal exchange. Taylor and Dean (1974) conducted a series of tracer experiments using Rhodamine dye in Biscayne Bay to calculate mixing coefficients on both the ocean and bay side of three creeks. Here, Rhodamine was injected continuously from a single release point over a half tidal cycle and its concentration was measured in the inlet for the following 45 hours. The decay of the dye concentration was used with flow velocity observations to calculate average mixing 
coefficients of $49 \%$ on the ocean sides and $55 \%$ on the bay sides of the three creeks. Tidal exchange is best expressed in this fashion as the combination of two fractions $\varepsilon_{\text {ocean }}$ and $\varepsilon_{\text {lagoon }}$, that describe the replacement of water on the ocean side and lagoon side of an inlet.

The ocean exchange fraction is the fraction of the tidal prism that exits the system on an ebb and remains in the ocean throughout the following flood as originally described by Stommel and Farmer. $\varepsilon_{\text {ocean }}$ can be quantified through a dye experiment through the equation

$$
\varepsilon_{\text {ocean }}=\frac{m_{\text {out }}-m_{\text {in }}}{m_{\text {out }}} .
$$

where $m_{\text {out }}$ and $m_{\text {in }}$ are the masses of dye that are transported out of and into the lagoon starting from high water during successive ebb and flood tides, respectively. In this type of experiment the tracer must initially be distributed uniformly throughout the lagoon. The lagoon exchange fraction is the fraction of the tidal prism that enters the system on a flood and remains within it throughout the following ebb. $\varepsilon_{\text {lagoon }}$ can be quantified through a similar type of dye experiment through the equation

$$
\varepsilon_{\text {lagoon }}=\frac{m_{\text {in }}-m_{\text {out }}}{m_{\text {in }}} .
$$


where $m_{\text {in }}$ and $m_{\text {out }}$ are the masses of dye that are transported into and out of the lagoon starting from low water during successive flood and ebb tides, respectively. In this type of experiment the tracer must initially be distributed uniformly throughout the ocean. Note that $m_{\text {in }}$ and $m_{\text {out }}$ vary depending on the initial conditions of the experiment, but qualitatively describe the same processes, i.e the mass of dye entering and exiting the lagoon. Tracer experiments to quantify both exchange fractions for a variety of tidal inlet geometries are simulated in Delft3D. The results from these simulations are presented in Table 2. For the ocean exchange fraction (Fig. 2A, 2B), the lagoon water (water that is initially located inside the lagoon) is uniformly seeded with dye at the start of the ebb flow and its flux is measured through the inlet mouth during an ebb and flood cycle. The procedure is repeated for the lagoon exchange fraction (Fig. 2C, 2D), except in this case the seawater is seeded uniformly at the start of the flood flow. High exchange fractions are primarily the result of flood and ebb waters being transported away from their respective withdrawal zones. For an inlet that effectively transports its ebb water away from the inlet mouth, a small percentage returns on the following flood. In nature this is likely influenced by the physical processes that control alongshore currents such as wave breaking. This corresponds to a flattening of the transport curve (Fig. 2A) after the tide switches at $t \approx 6.8 \mathrm{hr}$. For a lagoon exchange fraction (Fig. 2C), the same feature is visible except here it represents an inlet that can transport flood water far into the lagoon away from the landward entrance to the inlet. On the interior side of the inlet the influence of waves is minimal and the processes that control lagoon circulation such as wind likely become more significant. For an inlet with low exchange fractions, the transport curves appear more 
sinusoidal with flattening occurring later in the tidal cycle (Fig. 2B, 2D). This delay represents the time it takes for the volume of water in the inlet to empty during the ebb. Note, for an infinitely long inlet the transport curve would take the shape of a sine wave and the lagoon exchange fraction would approach zero.

\subsection{Transport Model}

A simple transport model is developed and compared to Delft3D to better understand how tidal exchange controls residence time. On each tidal cycle, a volume of water enters and exits a lagoon through the inlet mouth. This volume is the tidal prism and for inlet systems that exhibit a uniformly fluctuating basin water level it can be approximated by multiplying the basin surface area by its tidal range (twice the tidal amplitude). The advection of the tidal prism through the inlet drives the transport of seawater into the lagoon and lagoon water out to the sea. Previous tidal prism models (Dyer 1973, van de Kreeke 1983) utilize the principal of tidal flow asymmetry to quantify tidal exchange based on Stommel \& Farmer (1952). These models assume that a fraction $\left(\varepsilon_{\text {ocean }}\right)$ of the tidal prism that leaves the lagoon on an ebb tide will be replaced with seawater on the following flood tide. In these models the seawater that enters during the flood is typically assumed to be mixed completely with the remaining lagoon water. This assumption can lead to an over-prediction of tidal exchange. Because flooding waters do not always reach the inland portion of a lagoon, mixing is not always complete. Hence, the inclusion of the lagoon exchange fraction $\left(\varepsilon_{\text {lagoon }}\right)$ is more appropriate. 
To better understand how both of these fractions contribute to tidal exchange, lagoon water is tracked with dye in a simple transport model. The model begins at high water with a lagoon that is uniformly filled with dye of concentration $c_{0}$ and an ocean that contains no dye. The total mass of dye in the lagoon is expressed in terms of the initial concentration as $M_{0}=c_{0} V+c_{0} P$, where $\mathrm{V}$ represents the volume of water in the lagoon at low tide. The mass transport of dye is calculated after multiple tidal cycles by considering the ocean exchange and lagoon exchange fractions. Starting from high water, the mass of dye that exits the lagoon $\left(m_{\text {out }, 1}\right)$ on the first ebb is:

$$
m_{\text {out }, 1}=P c_{0}
$$

of which a fraction of the mass returns on the next flood tide $\left(m_{i n, 1}\right)$ based on the ocean exchange fraction (Eq. 3a):

$$
m_{\text {in }, 1}=\left(1-\varepsilon_{\text {ocean }}\right) m_{\text {out }, 1}
$$

Following Eq. 3b, a fraction $\left(1-\varepsilon_{\text {lagoon }}\right)$ of the dye that enters the lagoon on the flood returns to the ocean during the following ebb and a fraction $\left(\varepsilon_{\text {lagoon }}\right)$ will stay in the lagoon and by the end of the ebb mixes with the lagoon water. At times of low water the lagoon waters are assumed to be completely mixed. Accordingly, the mass transport out of the lagoon on the second ebb is 
$m_{\text {out }, 2}=\left(1-\varepsilon_{\text {lagoon }}\right) m_{\text {in }, 1}+\varepsilon_{\text {lagoon }} P c_{0}$

(6)

Substituting Eq. 5 into Eq. 6 leads to,

$$
m_{\text {out }, 2}=P C_{0}-\varepsilon_{\text {ocean }} P C_{0}+\varepsilon_{\text {ocean }} \varepsilon_{\text {lagoon }} P C_{0}
$$

Substituting Eq. 4 for the first terms on the right hand side gives,

$$
m_{\text {out }, 2}=m_{\text {in }, 1}+\varepsilon_{\text {ocean }} \varepsilon_{\text {lagoon }} P C_{0}
$$

which leads to an expression for the change in mass of dye over one tidal cycle (between successive low tides) that includes both contributions of the tidal exchange fractions,

$$
\Delta M=m_{\text {out }, 2}-m_{\text {in }, 1}=\varepsilon_{\text {ocean }} \varepsilon_{\text {lagoon }} P C_{0} .
$$

The new mean concentration of dye in the basin at low water can then be expressed as a function of the previous concentration using the generalized expression,

$$
c_{n}=c_{n-1}-\frac{\varepsilon_{\text {ocean }} \varepsilon_{\text {lagoon }} P C_{n-1}}{V}
$$


where $c_{n}$ and $c_{n-1}$ designate the mean concentrations in the lagoon after $n$ and $n-1$ tidal cycles. The general expression for the mass of dye that enters the system on the $n^{\text {th }}$ flood $\left(m_{i n, n}\right)$ is,

$$
m_{i n, n}=\left(1-\varepsilon_{\text {ocean }}\right) m_{\text {out }, n},
$$

The general expression for the mass of dye that exits on the $n^{\text {th }}$ ebb $\left(m_{\text {out }, n}\right)$ is,

$$
m_{\text {out }, n}=\left(1-\varepsilon_{\text {lagoon }}\right) m_{i n, n-1}+\varepsilon_{\text {lagoon }} P c_{n-1} .
$$

Expressing Eq. 10 in terms of the mass of dye in the lagoon is,

$$
M_{n}=M_{n-1}\left(1-\frac{\varepsilon_{\text {lagoon }} \varepsilon_{\text {ocean }} P}{V}\right),
$$

where $M_{n-1}$ and $M_{n}$ represent the total mass of dye in the lagoon at low water after $n-1$ and $n$ tidal cycles, respectively. Applying a Taylor expansion to the change in mass of dye over one tidal cycle gives:

$$
M_{n}=M_{n-1}+\left.T \frac{d M}{d t}\right|_{n-1}
$$


where $T$ is the tidal period. Combining Eq. 13 with Eq. 14 leads to the differential equation:

$$
\left.T \frac{d M}{d t}\right|_{n-1}=-M_{n-1}\left(\frac{\varepsilon_{\text {lagoon }} \varepsilon_{\text {ocean }} P}{V}\right),
$$

with a general form of:

$$
\frac{d M}{d t}=-\frac{\varepsilon_{\text {lagoon }} \varepsilon_{\text {ocean }} P M}{V T} .
$$

The solution takes the form of an exponential decay:

$$
M(t)=M_{0} \exp \left(-\frac{\varepsilon_{\text {lagoon }} \varepsilon_{\text {ocean }} P t}{V T}\right),
$$

where $t$ is time. Eq. 17 implies that both exchange fractions play an equal role in determining the flushing characteristics and subsequent residence times in a lagoon through tidal exchange. If the mass of dye in the basin decays exponentially in time, the mean residence time in the basin is the e-folding time scale (van de Kreeke, 1983). In that case referring to Eq. 17 leads to:

$$
\bar{T}_{r}=\frac{T}{\varepsilon_{\text {lagoon }} \varepsilon_{\text {ocean }}} \frac{V}{P} .
$$


A form of the solution when assuming complete mixing at high water is common in the literature. Referring to Eq. 12 this implies that $\varepsilon_{\text {lagoon }}=1$ (Bolin and Rhode 1973, van de Kreeke 1983, Prandle 1983, Monsen et a/2002, Arneborg 2004, Delhez et a/2004).

To approximate the product of the tidal exchange fractions, first a relationship with the physical process that controls them must be determined. Because the tidal exchange fractions broadly represent the magnitude of water replacement and mixing on each tidal cycle, they should scale with the tidal flow in the inlet. Stronger tidal flows result in greater renewal due to tidal asymmetries (e.g Stommel and Farmer, 1952) and greater mixing caused by more energetic shear flow. To examine this hypothesis, the relationship between the product of the tidal exchange fractions and the Reynolds number ( $\mathrm{Re}$ ) of the tidal flow is explored. A tangent hyperbolic function is fit to the modeling data in the least squares sense, resulting in the relationship,

$$
\varepsilon_{\text {ocean }} \varepsilon_{\text {lagoon }}=\tanh \left(\frac{\mathrm{Re}}{1.06 \times 10^{10}}\right),
$$

which fits the Delft3D results with $R^{2}=0.89$. The Reynolds number here is defined as,

$$
\operatorname{Re}=\frac{\hat{U l}}{v},
$$


where $\hat{U}$ is the maximum tidal velocity in the inlet averaged between the ebb and flood, $v$ is the kinematic viscosity of saltwater, and $l$ is the characteristic length scale for periodically reversing flows in a tidal inlet as defined by Wilkinson (1978),

$l=\left(\hat{U}^{2} T^{2} w\right)^{1 / 3}$

where $w$ is the inlet width. From Eq. 18-21 it follows that the residence time is a function of the parameters $\hat{U}, P, V, T, w$, and $v$.

\subsection{Model Scenarios}

In Section 2.5 the residence time is shown to be a function of the basin volume, the inlet width, the tidal period, and the hydrodynamic parameters $\hat{U}, P$, and $v$. The tidal period and volume of the basin are properties of the system that exhibit little temporal variability, whereas the hydrodynamic parameters are influenced by the geometry of the inlet which can experience significant morphological changes on the seasonal time scale (Ranasinghe and Pattiaratchi, 1998, Cayocca, 2000). Further, the exchange fractions are also thought to be influenced by hydrodynamic processes that vary on the tidal period time scale. To examine these relationships, various inlet geometries are studied. The lagoon dimensions, offshore bathymetry and tidal forcing are kept constant to isolate the effect that the inlet geometry has on tidal exchange and residence time. To do this, the inlet length, width and depth are varied while all other parameters of the model are kept constant. The dimensions of each inlet are presented in Table 1. 


\section{Results}

\subsection{Residence Time and Tidal Exchange}

The residence time distribution for each inlet geometry is calculated with Delft3D and an example distribution is presented in Fig. 3A. Residence time varies proportionally with along-inlet distance $(X)$ from the inlet opening. In the cross-inlet direction $(\mathrm{Y})$, there is more variability. In general, the regions near the inlet exhibit residence times that are on the order of 10 times shorter than those on the inland side of the lagoon. This distribution shape is attributed to the symmetrical nature of the system and the presence of a strong flood jet. Although in nature the presence of obstacles such as flood deltas and islands would likely hinder the formation of such a jet, they can occur and have been shown to promote mixing and reduce residence times (Stroup and Meyers, 1974). Next, the residence time distributions are spatially averaged and compared to the mean residence time from Eq. 18 in Table 2. For these calculations, the lagoon volume at mean sea level $\left(V=6.9 \times 10^{7} \mathrm{~m}^{3}\right)$ and the tidal period of the lunar semi-diurnal tidal constituent $(T=12.41 \mathrm{hr})$ are used. Both the tidal prism and the exchange fractions are obtained from Delft3D simulations for each inlet geometry.

For the narrow inlets $(w \leq 200 m)$ with different inlet lengths, the ocean exchange fraction is approximately constant. For the short inlets $(L=1300 \mathrm{~m})$ with different inlet widths, the ocean exchange fraction is reduced with increasing inlet width. This reduction in the ocean exchange fraction is attributed to three characteristics 1) A wider inlet results in smaller peak ebb velocities that reduce the offshore extent of the ebb 
flow. 2) A widening of the inlet creates a wider ebb jet that increases the region of overlap between the ebb jet and flood withdrawal zone as described in the Stommel \& Farmer model. 3) A wider inlet creates an ebb jet with less shear instabilities and shear induced mixing as compared to a narrow inlet. This concept is visible when examining the ebb plumes from wide and narrow inlets (Fig. 3B, 3C). Here, uniformly distributed dye is used to trace lagoon water. The narrower inlets create plumes with more shear induced eddies, more mixing on the ocean side of the inlet, and higher exchange fractions. The lagoon exchange fraction similarly correlates with the magnitude of the peak flood velocity for all inlet geometries. Stronger flood velocities allow flooding water to advect farther into the lagoon away from the ebb withdrawal zone, resulting in greater exchange due to tidal flow asymmetries. Stronger flood flows also promote more mixing in the lagoon, further promoting higher lagoon exchange fractions. Mehta and Zeh (1980) show how weak flood velocities reduce the inland extent of flooding water in Apalachicola Bay.

The spatially averaged residence time from Delft3D and the mean residence time from Eq. 18 are presented as a function of tidal exchange in Fig. 3D. Also included are the results from a modified expression for the mean residence time that assumes $\varepsilon_{\text {lagoon }}=1$, corresponding to complete mixing in the lagoon. This assumption leads to an under-prediction of the mean residence time as observed elsewhere in the literature (Dyer, 1973; Sanford et al 1992; Oliveira and Baptista 1997; Luketina 1998). The mean residence time in the lagoon varies inversely with the product of the tidal exchange fractions. The trend shows that an inlet that displays high exchange fractions is more efficient at transporting lagoon water out of the basin into the sea on each tidal cycle, 
resulting in a reduction in residence time. For the limiting case, as the tidal exchange fractions approach zero, residence time approaches infinity since there is no exchange between the lagoon and sea. To further examine how both tidal exchange fractions influence residence time, results from the transport model are compared to Delft3D in Appendix B.

\subsection{Inlet Hydraulics}

The tidal prism, the ratio of the ocean tidal amplitude to the lagoon tidal amplitude, the peak flood velocity and the peak ebb velocity for each inlet geometry are calculated in Delft3D and presented in Table 3. To relate the residence time to the hydraulic parameters for each inlet geometry the Keulegan repletion coefficient $k_{1}$ (Keulegan, 1967) and the ratio of the forcing frequency to the natural frequency of the basin $k_{2}$ (Mehta and Özsöy, 1978) are calculated. Because $k_{2} \square 1$ for all the inlet geometries studied, the response of the basin will not induce resonance and is considered to be friction dominated. $k_{1}$ is defined as:

$$
k_{1}=\frac{T A_{\text {avg }}}{2 \pi A_{b}} \sqrt{\frac{2 g}{a_{o}\left[k_{e n}+k_{e x}+\frac{f L}{4 R}\right]}} .
$$

where $A_{\text {avg }}$ is the average cross section area of the inlet, $L$ is the inlet length, $k_{e n}$ and $k_{e x}$ are entrance and exit energy loss coefficients, $f$ is the Darcy-Weisbach friction term, and $R$ is the hydraulic radius. The aptly named repletion coefficient describes the 
influence of the tide on filling an embayment. $k_{1}$ can be interpreted to describe inlet hydrodynamics with the assumption of a uniformly fluctuating water level in the basin often referred to in the literature as a 'pumping mode' (Mehta and Özsöy, 1978; Di Lorenzo, 1988). The Keulegan model also assumes a uniform velocity in the inlet and neglects variations of depth with tidal stage, whereas Delft3D does not. Accordingly, results from the Keulegan model should differ somewhat from Delft3D. Although not all inlet systems respond to tidal forcing in the way described by the Keulegan model, it does work for some real systems (MacMahan et al, 2014) and is a useful starting point that provides insight without the need of a numerical model or in situ observations.

The repletion coefficient is calculated using Eq. 22 for each inlet geometry. Values for the entrance and exit energy loss coefficients $\left(k_{e n}=0.1\right.$ and $\left.k_{e x}=1.0\right)$ are selected from the literature (O'Brien and Clark 1974, Army Corp. of Engineers 2008). These values correspond to an inlet entrance with moderately sharp curvature and an exit flow where kinetic head is completely lost. The dimensionless friction parameter $(f)$ is related to the Manning bottom roughness coefficient and the hydraulic radius through the expression:

$$
f=\frac{116 n^{2}}{R^{1 / 3}} .
$$

The same uniform value that is used in the Delft3D models $(n=0.028)$ is selected for consistency. This magnitude of bottom friction corresponds to a rippled sand bedform (Chow 1959, Benson and Dalrymple 1967). 
To calculate the mean residence time through Eq. 18, a priori knowledge of the inlet system's shape and the tidal conditions is required. With this information the tidal prism and tidal exchange fractions can be determined with the Keulegan model and empirical relationships presented here. The tidal prism is determined from the equation,

$$
P=2 a_{o} A_{b}\left(a_{b} / a_{o}\right)
$$

where $a_{o}$ is the amplitude of the tide in the ocean, $a_{b}$ is the amplitude of the tide in the lagoon, and $A_{b}$ is the surface area of the lagoon. The ratio of the tidal amplitudes $\left(a_{b} / a_{o}\right)$ is presented as a tabulated function of $k_{1}$ in Keulegan (1951). A curve fit that matches a tangent hyperbolic function to these data is performed in the least squares sense $\left(R^{2}=1.0\right)$, and provides an empirical relationship based on the repletion coefficient,

$$
\frac{a_{b}}{a_{o}}=\tanh \left(\frac{5}{4} k_{1}\right)
$$

The tidal amplitude ratios predicted with Eq. 25 are given in Table 3 and match those from Delft3D with $R^{2}=0.94$. Most mismatch is observed in inlets with $w \leq 150 m$. Substituting Eq. 25 into Eq. 24 results in tidal prism estimates that match Delft3D with $R^{2}=0.92$ for all the inlets studied. This approach does not take into account the volume of water that fills and empties the inlet, whereas the Delft3D method does. Including the 
surface area of each inlet in Eq. 24 improves the fit to $R^{2}=0.94$ (Fig. 4A). Small deviations from Delft3D are likely the result of Keulegan's assumption of a uniform velocity in the inlet and uniform filling of the lagoon. In Delft3D the velocity of the current is not constant in the cross-inlet direction nor does the water level fluctuate uniformly in the lagoon.

To determine the tidal exchange fractions, Eq. 19,20 and 21 are used. $\hat{U}$ is calculated with the Keulegan model through the expression,

$\hat{U}=\frac{\pi P C}{w d T}$,

where $d$ is the inlet depth and $C$ is a dimensionless number. Keulegan provides a table of values for $C$ and the corresponding repletion coefficients. A tangent hyperbolic function is fit to these data with $R^{2}=0.98$, resulting in the relationship,

$C=0.23 \tanh \left(0.46 k_{1}\right)+0.77$.

Substituting Eq. 24, Eq. 25 and Eq. 27 into Eq. 26 results in an expression for the maximum velocity in the inlet based on the repletion coefficient.

$\hat{U}=\frac{\pi C}{w d T}\left(2 a_{o} A_{b} \tanh \left(\frac{5 k_{1}}{4}\right)\right)$ 
The maximum flow velocities predicted with Eq. 28 are given in Table 3 and match those from Delft3D with $R^{2}=0.98$ (Fig. 4B). In this comparison, the average of the maximum ebb and flood velocity from Delft3D is used. These results suggest that Keulegan's model provides a good approximation for the hydrodynamics of simple single-inlet systems.

Applying these formulas to Eq. 18 leads to an expression for the mean residence time based on the Keulegan repletion coefficient $\left(k_{1}\right)$, the amplitude $\left(a_{o}\right)$ and period $(T)$ of the ocean tide, the width $(w)$ and depth $(d)$ of the inlet, the surface area of the lagoon $\left(A_{b}\right)$, the kinematic viscosity $(v)$ of the water:

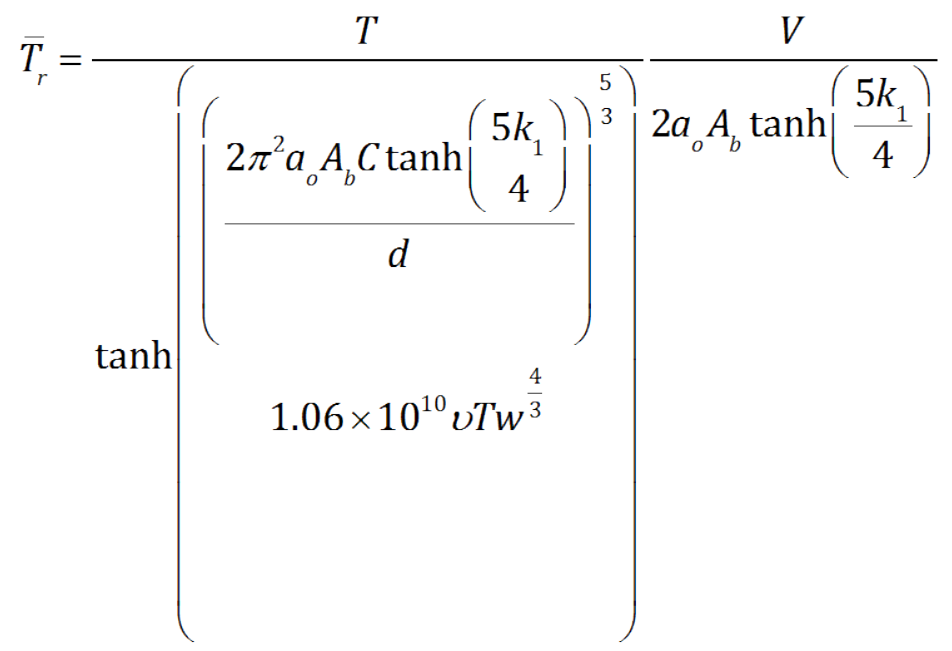

The mean residence time estimates derived from this relationship are presented in Table 2 and match those from the virtual tracer method in Delft3D with $R^{2}=0.91$ (Fig. 4C). The two approaches show the most agreement for the narrowest inlets ( $w \leq 200 m)$ and the least agreement for the widest inlets $(w \geq 400 m)$. Disagreement is attributed to 
the fact that the tidal exchange fractions are not constant. This concept is further explored in Appendix B.

Since the tidal forcing $\left(a_{o}\right)$ and lagoon geometry $\left(V, A_{b}\right)$ parameters are constant in the seventeen experiments, Eq. 29 shows that the observed variability in the mean residence time is primarily controlled by the repletion coefficient and to a lesser degree the width of the inlet. To explore this concept and to better understand the relationship between residence time and an inlet channel's degree of restriction, the dimensionless ratio $\bar{T}_{r} / T$ is plotted versus $k_{1}$ for each inlet channel geometry in Fig. 4D. For lower values of the repletion coefficient $\left(k_{1}<1\right)$, the Delft3D models produce higher residence times. In these scenarios the exchange of lagoon water with seawater is hindered by the restriction of the inlet and the reduction of the tidal prism dominates Eq. 18. For larger values of the repletion coefficient $\left(k_{1}>4\right)$, the Delft3D models also produce high residence times. Here, the inlet experiences little restriction and the tidal prism achieves its maximum possible value based on the size of the lagoon and the amplitude of the tide. Once the tidal prism is maximized, further broadening of the inlet leads to weaker tidal flows that result in smaller tidal exchange fractions that dominate Eq. 18. Residence time is minimized for inlets that are restricted enough to produce strong tidal flows, but broad enough to prevent a substantial reduction in the tidal prism. The following empirical relationship is reached by fitting the residence time model results to each inlet's repletion coefficient using the nonlinear least-squares algorithm in Matlab: 


$$
\frac{\bar{T}_{r}}{T}=\frac{1}{k_{1}}\left(\left(k_{1}-0.77\right)^{3}+4.70\right)
$$

This relationship matches the data with $R^{2}=0.96$ and requires only one variable $\left(k_{1}\right)$ to reach a mean residence time estimate. The equation suggests that residence time is minimized for $k_{1}=1.78$.

\section{Discussion and Conclusions}

Modeling studies of idealized tidal inlet systems show that the process of tidal exchange controls residence time in a back-barrier lagoon and that the mean residence time is inversely proportional to tidal exchange. A new approach of quantifying tidal exchange defines this relationship (Eq. 18). Two tidal exchange fractions, one that quantifies the exchange of ebbing water with seawater and another that quantifies the exchange of flooding water with lagoon water are combined to describe the unique qualities of an individual inlet. Measuring these fractions in practice requires a substantial field experiment or a numerical model, making them challenging to acquire and not widely useful. To illustrate, Taylor and Dean (1974) conducted a series of tracer experiments using Rhodamine dye in Biscayne Bay to calculate mixing coefficients on both the ocean and bay side of three creeks. They observed the equivalent of a mean ocean exchange fraction of $\bar{\varepsilon}_{\text {ocean }}=0.49$ from twelve experiments and a mean lagoon exchange fraction of $\bar{\varepsilon}_{\text {lagoon }}=0.55$ from seven experiments. Here, Rhodamine was injected continuously from a single release point over a half tidal cycle and its 
concentration was measured in the inlet for the following 45 hours. The decay of the dye concentration was used with flow velocity observations to approximate mixing coefficients. Although this approach provides insight into exchange processes, the nonuniform distribution of tracer likely produces inaccurate exchange fraction results. In a virtual experiment, dye can be introduced instantaneously at the beginning of an ebb or flood in a uniform distribution, eliminating any bias associated with the dye injection procedure. If field observations or a numerical model aren't available, Keulegan's 0-D hydrodynamic model can be used to provide estimates of the tidal prism and the magnitude of the tidal flow based on the repletion coefficient. The product of the tidal exchange fractions are shown to scale with the maximum velocity in the inlet following Eq. 23, allowing for an expression for the mean residence time that is based on the tide and geometry of the inlet (Eq. 29).

The relationship between residence time and the repletion coefficient (Fig. 4D) suggests that the magnitude of tidal exchange in an inlet system is controlled by water replacement and mixing. Water replacement scales with the tidal prism, and for a constant basin size and tidal forcing, is controlled by the restriction of the inlet. As the inlet becomes almost entirely restricted, the tidal prism and magnitude of exchange approach zero and residence time approaches infinity. As the inlet is broadened past a critical value, $a_{b} / a_{0}$ approaches one in Eq. 24 and the tidal prism reaches its maximum value and remains constant. For the idealized conditions studied, mixing scales with the magnitude of the tidal velocity. Stronger flows draw ebb and flood waters farther away from their respective withdrawal zones and result in greater shear induced mixing. A more restricted inlet generally creates energetic flows while larger inlets have weaker 
flows. In extreme cases where the inlet becomes so restricted that friction dominates, the flow velocity, discharge and tidal prism are reduced. With these competing processes, the residence time is minimized for inlets that are restricted enough to produce strong tidal velocities while broad enough to prevent a substantial reduction in the tidal prism.

Implementing virtual tracers in a numerical model is needed to produce highly resolved residence time distributions. These distributions show that the spatial variance of residence time is high even in idealized geometries and, although laborious to produce, are valuable in their ability to understand the fate of contaminants in the coastal zone. The mean residence times for different inlet geometries using Eq. 18 compare well with the spatial averages of the residence time distribution from the virtual dye method in Delft3D. When comparing these results in Fig. 3D, the continuous residence time curves (solid and dashed lines) use a constant mean tidal prism from all the inlet geometries while the results from Delft3D (circular points) have a varying tidal prism. A constant tidal prism is applied to Eq. 18 to show the trend between residence time and tidal exchange with all other parameters equal. For a more precise comparison, we direct the reader to the mean residence time values in Table 2 where the variation of the tidal prism is taken into account in both cases. The two approaches show the most agreement for narrow inlets with large exchange fractions, and less agreement for wide inlets with low exchange fractions. This discrepancy is explored in Appendix B by comparing some results from the simple transport model to the Delft3D simulations. The simple transport model begins to deviate from Delft3D for wider inlets because of the assumption that the tidal exchange fractions are constant. Especially for 
wider inlets with less energetic flows, the flood withdrawal zone can gradually fill with lagoon water over multiple tidal cycles. This causes a reduction in the ocean exchange fraction from one tidal cycle to the next and an overall decline in exchange (Signell and Butman, 1992).

\section{Acknowledgements}

We thank the National Defense Science \& Engineering Graduate Fellowship and the Office of Naval Research (N000141110376; N0001411WX20962; N0001412WX20498) for funding this work.

\section{Appendix A - Virtual Dye Residence Time Calculation}

The tidally averaged residence time for a particular location is calculated using the cumulative advection of dye out of the lagoon in Fig. A1. The mass of the unique dye constituent for that location that leaves the system through the inlet mouth is measured (blue line). The total mass of that dye that remains in the basin (dashed black line) can be calculated as the difference between the total mass released at the source (red line) and the mass that has left the lagoon. The tidally-averaged flux of dye leaving the lagoon is calculated as the slope of the advection curve measured between two successive low tides. At equilibrium, the flux of dye leaving the lagoon is equal to that introduced at the source such that the total amount of dye in the lagoon remains constant. When this condition is met, the tidally-averaged residence time for that release point can be calculated using Eq. 1. 


\section{Appendix B - Simple Transport Model vs. Delft3D}

Using the ocean and lagoon exchange fractions for each inlet geometry, the simple transport model is compared to Delft3D. Two scenarios are included in the transport model, one that includes both tidal exchange fractions and one that assumes complete mixing in the lagoon $\left(\varepsilon_{\text {lagoon }}=1\right)$. All models are initiated at high water with dye uniformly distributed in the lagoon and run until all of the dye is flushed out and transported to the sea through tidal exchange. An example showing the distribution of dye from the baseline inlet geometry after 1, 2, 6 and 15 tidal cycles is presented in Fig. A2.

Time series of the cumulative transport of dye out of the lagoon from Delft3D and the two transport model scenarios are shown in Fig. A3. For narrow $(w \leq 200 m)$ inlets (Fig. A3A), both transport model scenarios show good agreement with Delft3D, an expected result since the lagoon exchange fractions for these inlets is nearly $100 \%$. For longer inlets that produce lower lagoon exchange fractions, the assumption of complete mixing leads to an over prediction of transport (Fig. A3B). In these scenarios, much of the water that enters the lagoon on the flood will leave on the following ebb, resulting in less exchange and longer residence times. For wider $(w \geq 400 m)$ inlets (Fig. A3C) the transport model with both exchange fractions begins to deviate from Delft3D after three tidal cycles. This discrepancy is caused by the inability of the transport model to account for the accumulation of dye in the flood withdrawal zone and the assumption that the exchange fractions are constant in time. Because the ebb velocity in a wider inlet is lower, the ability of the inlet to advect lagoon water far offshore is reduced and the resulting ocean exchange fraction is smaller. Over multiple tidal cycles, the less 
energetic ebb flow can lead to the gradual "filling" of the flood withdrawal zone with lagoon water (Signell and Butman, 1992) and a longer term decline in total exchange. The transport model does not take this into account whereas a model like Delft3D that resolves the fluid motion will. To further explore this, the product of the two exchange fractions is expressed in terms of the change in mean dye concentration in the lagoon from one tidal cycle to the next using Eq. 10,

$$
\varepsilon_{\text {lagoon }} \varepsilon_{\text {ocean }}=\frac{V\left(1-\frac{c_{n}}{c_{n-1}}\right)}{P} .
$$

The mean dye concentration in the lagoon at high water after each tidal cycle is calculated in the Delft3D model and applied to Eq. 31. The temporal variation in the product of the exchange fractions is then compared to the constant values implemented in the transport model. Two characteristic results are presented in Fig. A4, one from a narrow inlet (A4A) and another from a wide inlet (A4B). For the narrow inlet, the product of the exchange fractions is relatively constant in time, suggesting that the constant values implemented in the transport model adequately describe the physics simulated in Delft3D. This result is confirmed by good agreement in Fig. A3A and A3B. For the wider inlet, the product of the exchange fractions varies in time, with a sudden drop in exchange occurring within the first few tidal cycles. Because the transport model implements a constant value that is based on a dye simulation over one tidal cycle, it is not adequately describing this time dependence. This is also confirmed by the mismatch seen in Fig. A3C. Despite this, the transport model that includes both tidal exchange 
fractions shows better agreement with Delft3D than one that assumes complete mixing in the lagoon for all scenarios studied.

\section{References}

Anderson, I.C., McGlathery, K.J., Tyler, A.C., 2003. Microbial mediation of reactive nitrogen transformations in a temperate lagoon. Mar. Ecol. Prog. Ser. 246, 73-84.

Arega, F. and A. W. Badr. 2010. Numerical Age and Residence-Time Mapping for a Small Tidal Creek: Case Study. Journal of Waterway, Port, Coastal, and Ocean Engineering, Vol. 136, No. 4.

U.S. Army Corps of Engineers. 2002. Coastal Engineering Manual, Part II, Chapter 6, "Hydrodynamics of tidal inlets," EM 1110-2-1100, Washington, DC.

Arneborg, L. 2004. Turnover times for the water above sill level in Gullmar Fjord. Continental Shelf Research, 24, 443-460.

Awaji, T., N. Imasato, K. Hideaki. 1980. Tidal exchange through a strait: A numerical experiment using a simple model basin. Journal of Physical Oceanography Vol. 10, 1499-1508.

Banas, N. S., B. M. Hickey. 2005. Mapping exchange and residence time in a model of Willapa Bay, Washington, a branching, macrotidal estuary. Journal of Geophysical Research, Vol. 110, C11011

Benson, M. A., T. Dalrymple., 1967. General field and office procedures for indirect discharge measurements: U.S. Geological Survey Techniques of Water-Resources Investigations, Book 3, Chap. A1, 30 p.

Bolin, B., H. Rodhe. 1972. A note on the concepts of age distribution and transit time in natural reservoirs. Tellus, Vol. 25, Issue 1, pp. 58-62.

de Brauwere, A., de Brye, B., Blaise, S., Deleersnijder, E., 2011. Residence time exposure time, and connectivity in the Scheldt Estuary. Journal of Marine Systems 84, 85-95.

Brown, E.I., "Flow of Water in Tidal Canals," Proc. ASCE, 96, 747-834, 1932.

Bruun, P., A. J. Mehta, I. G. Jonsson. 1978. Stability of Tidal Inlets: theory and engineering. Elsevier Scientific Publishing Co., Amsterdam, The Netherlands. 
Cayocca, F., 2001. Long-term morphological modelling of a tidal inlet: the Arcachon Basin, France. Coastal Engineering 42, 115-142.

Chadwick, D. B., J. L. Largier. 1999. Tidal exchange at the bay-ocean boundary. Journal of Geophysical Research, Vol. 104. C12, pp. 29,901-29,924.

Chow, V. T., 1959. Open-inlet hydraulics. New York, McGraw-Hill, 680 p.

Di Lorenzo, J.L., 1988. The overtide and filtering response of small inlet-bay systems. In: Aubrey, D.G., Weishar, L. (Eds.), Hydrodynamics and Sediment Dynamics of Tidal Inlets. Springer-Verlag, pp. 24-54

Dean, R.G., Taylor, R.B., 1972. Numerical modeling of constituent transport in bay systems, Proc. 13th ICCE, ASCE, New York, 2217-2240.

Delhez, E. J. M. 2013. On the concept of exposure time. Continental Shelf Research 71 (2013) 27-36.

Delhez, E. J. M., A. W. Heemink, E. Deleersnijder. 2004. Residence time in a semienclosed domain from the solution of an adjoint problem. J. Estuarine, Coastal and Shelf Science, 61, 691-702.

Dyer, K. 1973. Estuaries - A Physical Introduction, London: Wiley- Interscience.

Elias, E. P. L., G. Gelfenbaum, and A. J. Van der Westhuysen (2012), Validation of a coupled wave-flow model in a high-energy setting: The mouth of the Columbia River, J. Geophys. Res., 117, C09011

Fischer, H.B., E.J. List, R.C.Y. Koh, J. Imberger, and N.H. Brooks. 1979. The dynamics of the vertical Mixing in Inland and Coastal Waters, 483 pp.

Frey, R. W., P. B. Basan. 1985. Coastal salt marshes. In: Davis Jr., R.A. (Ed.), Coastal Sedimentary Environments. Springer-Ver- lag, New York, pp. 225-301.

Gillibrand, P. A., M.E. Inall, E. Portilla, P. Tett. 2013. A box model of the seasonal exchange and mixing in Regions of Restricted Exchange: Application to two contrasting Scottish inlets. Environmental Modelling \& Software 43, 144-159

Glaeser D. J., 1978. Global distribution of barrier islands in terms of tectonic setting. Journal of Geology 86, 283-197

Jarrett, J. T. 1975. Analyses of the Hydraulic Characteristics of Tidal Inlets, Unpublished memorandum for record, U.S. Army Engineer Waterways Experiment Station, Vicksburg, MS. 
Keulegan, G.H., Tidal Flow in Entrances, U.S. Army Corps of Engineers, Committee on Tidal Hydraulics, Tech. Bull. 14, Vicksburg, 1967.

Keulegan, G.H., 1951. Water-level fluctuations of basins in communication with seas, Third Progress Report on Tidal Flow in Entrances, Beach Erosion Board, Corps of Engineers, Depart- ment of the Army, U.S. Department of Commerce, National Bureau of Standards Report 1146A.

Kjerfve, B. 1986. Comparative oceanography of coastal lagoons. In: Wolfe DA (ed) Estuarine Variability (pp 63-81). Academic Press, New York.

Kjerfve, B., 1994. Coastal lagoon processes. Elsevier, Amsterdam.

Lee, J.H., Pang, I. C., Moon, I. J., Ryu, J. H., 2011. On physical factors that controlled the massive green tide occurrence along the southern coast of the Shandong Peninsula in 2008: a numerical study using a particle-tracking experiment. J. Geophys. Res. 116 (C12036).

Lesser, G. R., J. A. Roelvink, J. A. T. M. Van Kester, and G. S. Stelling. 2004. Development and validation of a three-dimensional morphological model, Coastal Eng., 51, 883-915.

Luketinam D. 1998. Simple tidal prism models revisited. Estuar. Coasta. Shelf Sci. 46: 77-84.

MacMahan, J., J. van de Kreeke, A. J. H. M. Reniers, S. Elgar, B. Raubenheimer, E. Thornton, M. Weltmer, P. Rynne, J. Brown. 2014. Fortnightly tides and subtidal motions in a choked inlet. Estuarine, Coastal and Shelf Science. Voume 150. pp 325331.

Mehta, A. J., and Özsöy, E. 1978. "Inlet Hydraulics," Stability of Tidal Inlets: Theory and Engineering, P. Bruun, Elsevier Scientific Publishing Co., Amsterdam, The Netherlands, pp 83-161.

Mehta, A. J., and Zeh, T. A. 1980. Influence of a Small Inlet in a Large Bay. Coastal Eng., 4, 157-176.

Mitsch, W. J., J. G. Gosselink. 1993. Wetlands, 2nd ed. Van Nostrand Reinhold, New York. 722 pp.

Monsen, N. E., J. E. Cloern, L. V. Lucas, S. G. Monismith. 2002. A Comment on the Use of Flushing Time, Residence Time, and Age as Transport Time Scales. Limnology and Oceanography, Vol. 47, No. 5., pp. 1545-1553.

Mudge, S. M., J. D. Icely, A. Newton. 2008. Residence times in a hypersaline lagoon: Using salinuty as a tracer. Estuarine, Coastal and Shelf Science 77 (2), 278-284. 
O'Brien, M.P., 1931. Estuary Tidal Prism Related to Entrance Areas, Civil Engineering, Vol. 1, No. 8, pp 738-739.

O'Brien, M.P., R. R. Clark. 1974. Hydraulic constants of tidal entrances. Coastal Engineering 2, 1546-65

Oliveira, A, A. M. Baptista. 1997. Diagnostic modeling of residence times in estuaries. Water Resour. Res. 33: 1935-1946.

Orfila, A., A. Jordi, G. Basterretxea, G. Vizoso, N. Marba, C. M. Duarte, F. E. Werner, J. Tintore. 2005. Residence time and Posidonia oceanica in Cabrera Archipelago National Park, Spain. Continental Shelf Research 25, pp. 1339-1352.

Parker, D. S., Norris, D. P., and Nelson, A. W. 1972. Tidal Exchange at Golden Gate, J. Sanit. Eng. Div., 98(SA2)

Powell, M.A., R.J. Thieke and A.J. Mehta, 2006. Morphodynamic relationships for ebb and flood delta volumes at Florida's entrances. Ocean Dynamics 56: 295-307

Prandle, D. 1983. A modelling study of the mixing of 137Cs in the seas of the european continental shelf. Phil. Trans. R. Soc. Long. A 310, 407-436.

Pritchard, D. W., Salt Balance and exchange rate for the Chincoteague Bay, Chesapeake Sci., 1, 48, 1960

Ridderinkhof, H., J. T. F Zimmerman, M.E. Philippart. 1990. Tidal exchange between the north sea and Dutch Wadden Sea and mixing time scales of the tidal basins. Netherlands Journal of Sea Research 25(3): 331-350.

Safak, I., P.L. Wiberg, D.L. Richardson, M.O. Kurum. 2015. Controls on residence time and exchange in a system of shallow coastal bays. Continental Shelf Research 97, pp. $7-20$

Sanford, L. P., W. C. Boicourt, S. R. Rives. 1992. Model for estimating tidal flushing of small embayments. J. Waterw. Port Coast. Ocean Eng. 118: 635-654.

Sartor, J. D., G. B. Boyd, F. J. Agardy. 1972. Water pollution aspects of street surface contaminants. J. Water Pollution Control Fed., 46(3), 458-467.

Schumann, E. H., M. W. Pearce. 1997. Freshwater inflow and estuarine variability in the Gamtoos estuary, South Africa. Estuaries Vol. 20, No. 1, pp. 124-133

Seabergh, W. C. 2008. Hydrodynamics of Tidal Inlets. Coastal Engineering Manual, Part II, Hydrodynamics, Chapter II-6, Engineer Manual 1110-2-1100, U.S. Army Corps of Engineers, Washington, DC.

Signell, R. P, B. Butman, 1992. Modeling tidal exchange and dispersion in Boston harbor, J. Geophys. Res., 97, NO. C10, pp 15,591 - 15,606 
Stommel, $\mathrm{H}$ and $\mathrm{H}$. G. Farmer. 1952. On the nature of estuarine circulation, pp. 54, Woods Hole Oceanographic Institute, Mass.

Stroup. E. D. and G. A. Meyers. 1974. The Flood-Tide Jet in Fanning Island Lagoon. Pacific Science, Vol. 28, No. 3, pp. 211-223.

Surge, D. M., K. C. Lohmann. 2002. Temporal and spatial differences in Salinity and Water Chemistry in SW Florida estuaries: effects of human-impacted watersheds. Estuaries Vol. 25, No. 3, pp. 393-408

Swick, W., J. H. MacMahan, A.J.H.M. Reniers and E.B. Thornton. 2014. Observations and modeling of transverse mixing in a natural gravel-bed river. Journal of River Engineering, Vol. 2, Issue 9, $11 \mathrm{pp}$.

Taylor, R. B and R. G. Dean. 1974. Exchange Characteristics of Tidal Inlets. Section: Part IV: Coastal, Estuarine, And Environmental Problems, pp. 2268-2289

Uittenbogaard, R.E. and B. van Vossen, 2003: Subgrid-scale model for quasi-2D turbulence in shallow water. Proc. Shallow Flows. Delft, 16-18 June, Balkema, Rotterdam

van de Kreeke, J., 1983. Residence Time: Application to Small Boat Basins. Journal of Waterway, Port, Coastal and Ocean Engineering, Vol. 109, No. 4, pp. 416-428

Wang, Z.B., Louters, C., T., De Vriend, H.J., 1995. Morphodynamic modelling for a tidal inlet in the Wadden Sea. Marine Geology 126, 289-300.

Wijeratne, E. M. S., L. Rydberg. 2007. Modelling and observations of tidal wave propagation, circulation and residence times in Puttalam Lagoon, Sri Lanka. Estuarine, Coastal and Shelf Science 74, pp. 697-708

Wilkinson, D. L. 1978. Periodic flows from tidal inlets. Proceedings of the 16th International Coastal Engineering Conference, Hamburg (1978), pp. 1336-1346

Zimmerman, J. T. F. 1976. Mixing and flushing of tidal embayments in the western Dutch Wadden Sea Part 1: Distribution of salinity and calculation of mixing time scales. Netherlands Journal of Sea Research 10 (2): 149-191. 


\begin{tabular}{|c|c|c|c|}
\hline Experiment \# & $L_{|n|}$ & "., & $U_{[:]}$ \\
\hline 1 & 650 & 200 & 2.6 \\
\hline 2 & $\Re_{0}$ & 20 & 1.6 \\
\hline 3 & 30 & 20 & 2.0 \\
\hline 4 & 30 & 100 & 46 \\
\hline 5 & $3 \Omega$ & 200 & 26 \\
\hline 6 & 2000 & 20 & 46 \\
\hline 7 & 3090 & 100 & 46 \\
\hline 8 & 3800 & 100 & 56 \\
\hline 8 & 3000 & 150 & 26 \\
\hline 10 & 3900 & 20 & 46 \\
\hline 11 & 520 & 20 & 46 \\
\hline 12 & 550 & 20 & 26 \\
\hline 13 & 7800 & 200 & 26 \\
\hline 14 & 30 & 40 & 46 \\
\hline 15 & 30 & 600 & 46 \\
\hline 16 & 30 & 80 & if \\
\hline 17 & 330 & ' & 6 \\
\hline
\end{tabular}

Table 1: Summary of the inlet geometries from the Delft3D experiments. 


\begin{tabular}{|c|c|c|c|c|c|}
\hline Experiment \# & $\varepsilon_{\text {retam }}$ & 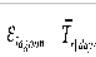 & Delft:D $\}$ & 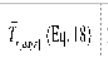 & 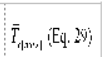 \\
\hline 1 & 0.92 & 0.90 & 3.30 & 2.78 & 3.30 \\
\hline 2 & 0.68 & 0.58 & v & 34.81 & 34.28 \\
\hline 3 & 0.87 & 0.84 & • & 6.88 & 7.46 \\
\hline 4 & 0.85 & 0.89 & 8.54 & 6.00 & 4.09 \\
\hline 5 & 0.92 & 0.86 & 3.60 & 2.99 & 3.58 \\
\hline 6 & 0.92 & 0.78 & 4.60 & 3.55 & 4.21 \\
\hline 7 & 0.83 & 0.73 & 11.68 & 10.95 & 7.80 \\
\hline 8 & 0.86 & 0.65 & 6.70 & 8.10 & 5.49 \\
\hline 9 & 0.87 & 0.73 & 5.58 & 5.62 & 5.54 \\
\hline 10 & 0.91 & 0.68 & 4.90 & 4.37 & 4.89 \\
\hline 11 & 0.91 & 0.56 & 6.20 & 5.65 & 5.60 \\
\hline 12 & 0.90 & 0.42 & 8.30 & 8.07 & 6.20 \\
\hline 13 & 0.90 & 0.28 & 13.20 & 12.76 & 6.89 \\
\hline 14 & 0.75 & 0.60 & 8.20 & 4.5 & 5.68 \\
\hline 15 & 0.43 & 0.46 & 32.20 & 10.31 & 8.63 \\
\hline 16 & 0.30 & 0.35 & 52.40 & 19.32 & 11.87 \\
\hline 17 & 0.19 & 0.28 & 94.30 & 36.09 & 15.19 \\
\hline
\end{tabular}

Table 2: Tidal exchange fractions and mean residence times for each inlet geometry. *The model could not reach a tidally averaged equilibrium and residence time solutions could not be reached. 


\begin{tabular}{|c|c|c|c|c|c|c|c|c|}
\hline Experiment \# & $k_{1}$ & $P_{\text {in }^{\prime}(}\left(\operatorname{Del} \int \mathrm{LS}\right)$ & $P_{n n^{*} \mid}\left(k_{1}\right)$ & $a_{i} / a_{i}$, (Delli.3D) & $a_{i} / a_{n}\left(k_{1}\right)$ & 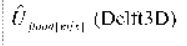 & $\hat{U}_{\text {stib, n:s:s, }}(\mathrm{Delft} 3 \mathrm{D})$ & $\hat{U}_{\mid m i s}\left(k_{1}\right)$ \\
\hline 1 & 1.73 & $1.55 \times 10^{7}$ & $1.53 \times 10^{7}$ & 0.96 & 0.97 & 1.28 & 1.03 & 1.07 \\
\hline 2 & 0.13 & $2.60 \times 10^{6}$ & $2.54 \times 10^{6}$ & 0.16 & 0.16 & 0.72 & 0.62 & 0.70 \\
\hline 3 & 0.39 & $7.10 \times 10^{8}$ & $7.14 \times 10^{0}$ & 0.44 & 0.45 & 1.05 & 1.00 & 1.01 \\
\hline 4 & 0.69 & $7.86 \times 10^{6}$ & $1.09 \times 10^{7}$ & 0.52 & 0.70 & 1.56 & 1.55 & 1.40 \\
\hline 5 & 1.39 & $1.51 \times 10^{7}$ & $1.48 \times 10^{7}$ & 0.93 & 0.94 & 1.13 & 0.97 & 1.02 \\
\hline 6 & 1.07 & $1.40 \times 10^{7}$ & $1.40 \times 10^{7}$ & 0.85 & 0.87 & 0.96 & 0.87 & 0.93 \\
\hline 7 & 0.45 & $5.38 \times 10^{8}$ & $8.12 \times 10^{6}$ & 0.37 & 0.51 & 1.05 & 1.06 & 1.01 \\
\hline 8 & 0.63 & $7.88 \times 10^{6}$ & $1.05 \times 10^{7}$ & 0.50 & 0.66 & 1.19 & 1.19 & 1.10 \\
\hline 9 & 0.68 & $1.00 \times 10^{7}$ & $1.11 \times 10^{7}$ & 0.64 & 0.69 & 1.00 & 0.96 & 0.95 \\
\hline 10 & 0.9 & $1.32 \times 10^{7}$ & $1.32 \times 10^{7}$ & 0.79 & 0.81 & 0.87 & 0.82 & 0.87 \\
\hline 11 & 0.79 & $1.24 \times 10^{7}$ & $1.26 \times 10^{7}$ & 0.73 & 0.76 & 0.81 & 0.76 & 0.81 \\
\hline 12 & 0.72 & $1.17 \times 10^{7}$ & $1.21 \times 10^{7}$ & 0.68 & 0.72 & 0.76 & 0.72 & 0.78 \\
\hline 13 & 0.66 & $1.11 \times 10^{\prime}$ & $1.16 \times 10^{\prime}$ & 0.64 & 0.68 & 0.72 & 0.68 & 0.74 \\
\hline 14 & 2.79 & $1.76 \times 10^{7}$ & $1.60 \times 10^{7}$ & 1.12 & 1.0 & 0.66 & 0.62 & 0.59 \\
\hline 15 & 4.19 & $1.75 \times 10^{7}$ & $1.63 \times 10^{7}$ & 0.96 & 1.0 & 0.45 & 0.44 & 0.41 \\
\hline 16 & 5.58 & $1.76 \times 10^{7}$ & $1.66 \times 10^{7}$ & 1.03 & 1.0 & 0.34 & 0.34 & 0.32 \\
\hline 17 & 6.98 & $1.78 \times 10^{7}$ & $1.68 \times 10^{7}$ & 1.00 & 1.0 & 0.27 & 0.27 & 0.26 \\
\hline
\end{tabular}

Table 3: Inlet hydraulic parameters derived from Delft3D simulations and Keulegan's model. 

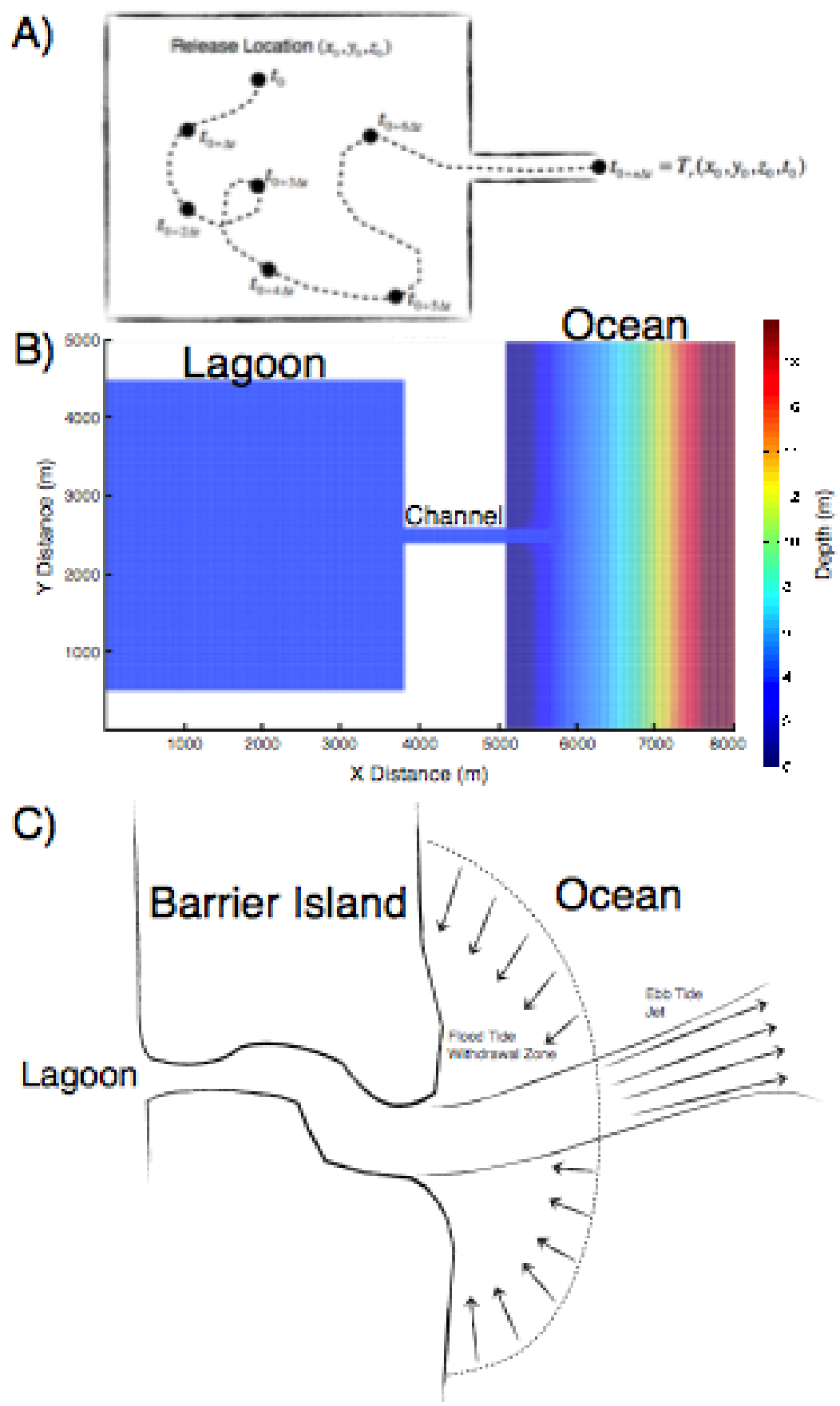

Figure 1: A diagram illustrating the definition of residence time $(A)$ and the baseline model bathymetry and grid of a simple lagoon based on Florida inlets (B). If a Lagrangian particle is released at a location $\left(x_{0}, y_{0}, z_{0}\right)$ at time $t=t_{0}$, the residence time is the time it takes that particle to exit the basin and enter the ocean. Tidal asymmetries on the ocean side of an inlet $(\mathrm{C})$ were first used to explain the process of tidal exchange. 


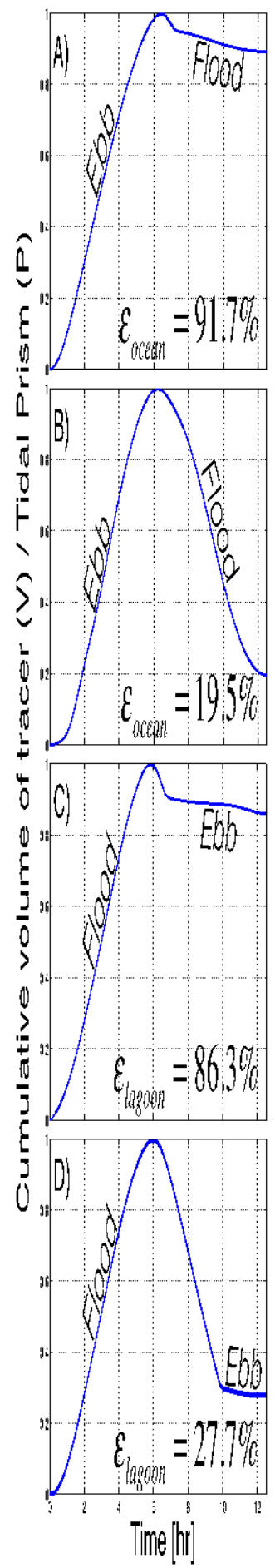

Figure 2: Delft3D model results to calculate $\varepsilon_{\text {ocean }}$ and ${ }^{\varepsilon_{\text {lagoon }}}$ using a virtual tracer show how inlet geometry influences tidal exchange. The ocean exchange fraction for an inlet with a narrower $(w=200 m)$ inlet $(A)$ is higher than that for a wider $(w=1000 m)$ inlet (B). The lagoon exchange fraction for an inlet with a shorter $(L=2600 \mathrm{~m})$ inlet $(C)$ is higher than that for a longer $(L=7800 m)$ inlet (D). 

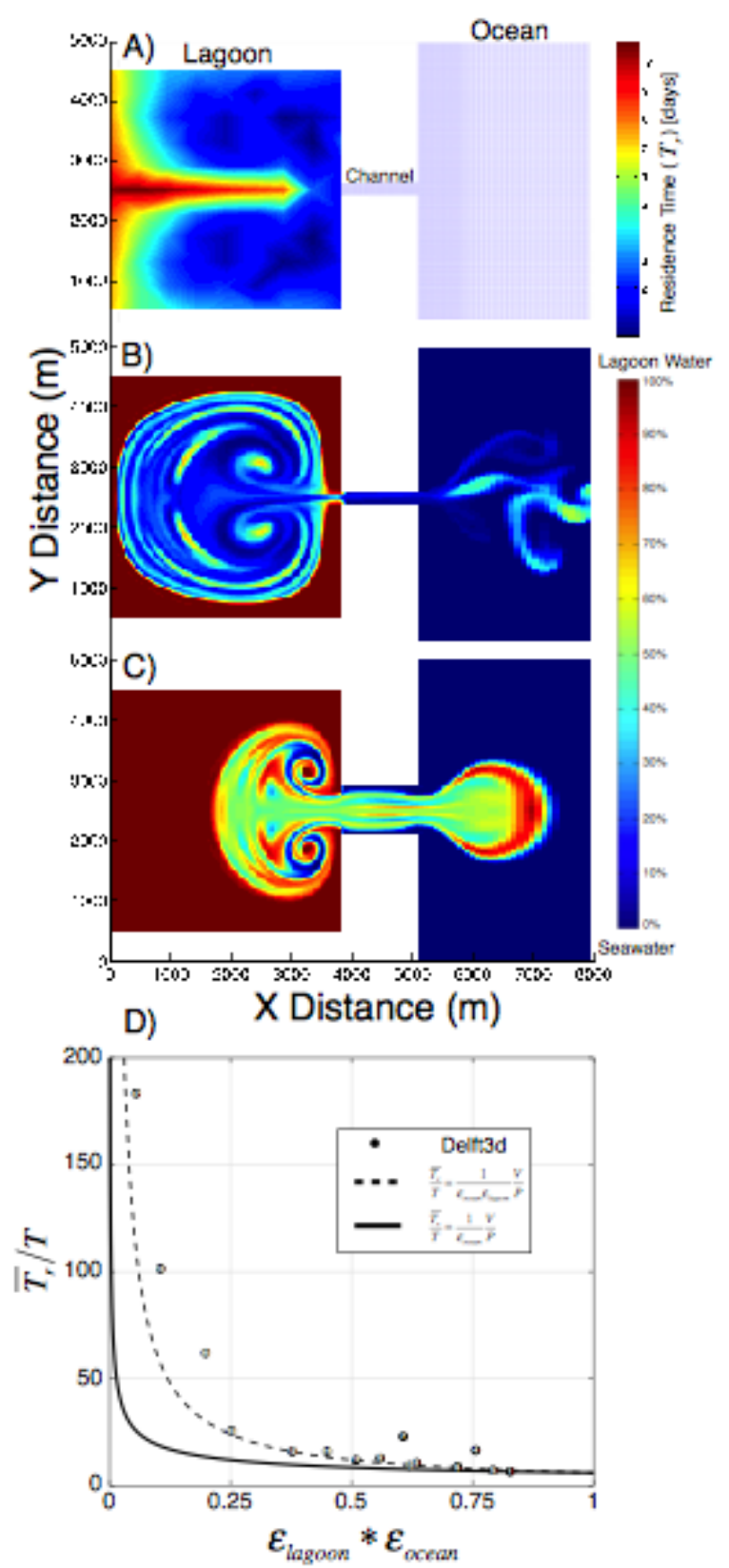

Figure 3: An example residence time distribution (A) for the baseline inlet dimensions $(w=200 \mathrm{~m}, \mathrm{I}=1300 \mathrm{~m})$. Residence time is controlled in part by the tidal exchange fractions. The distribution of lagoon water (red) and seawater (blue) in a narrow inlet (B) and a wide inlet $(\mathrm{C})$ after 4 tidal cycles illustrates how the dimensions of the inlet influence tidal exchange and mixing. In both examples the lagoon and inlet are initially seeded uniformly with dye. The mean residence time is inversely proportional to the product of the tidal exchange fractions (D). Results using the virtual tracer method in Delft3D for each experiment (numbered dots) are compared to Eq. 18 that includes both exchange fractions (dashed line) and that assumes $\varepsilon_{\text {lagoon }}=1$ (solid line). Neglecting the lagoon exchange fraction leads to an under-prediction of the residence time. 

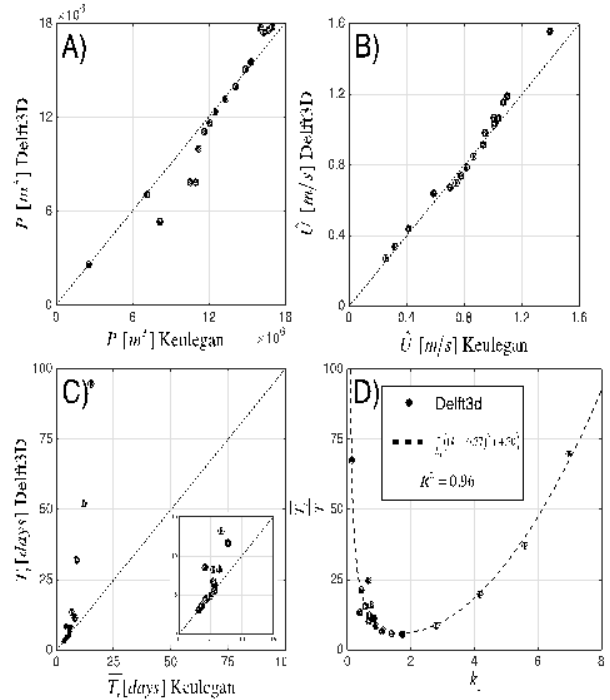

Figure 4: Comparison of the tidal prisms $(A)$, velocity amplitudes in the inlet $(B)$, and mean residence times $(C)$ from Delft3D simulations with results derived from Keulegan's model. An empirical relationship between the non-dimensional mean residence time and the repletion coefficient $(\mathrm{D})$ fits the model results with $R^{2}=0.96$ and suggests that residence time is minimized for $k_{1} \approx 1.78$. The experiment number is listed for each data point. 


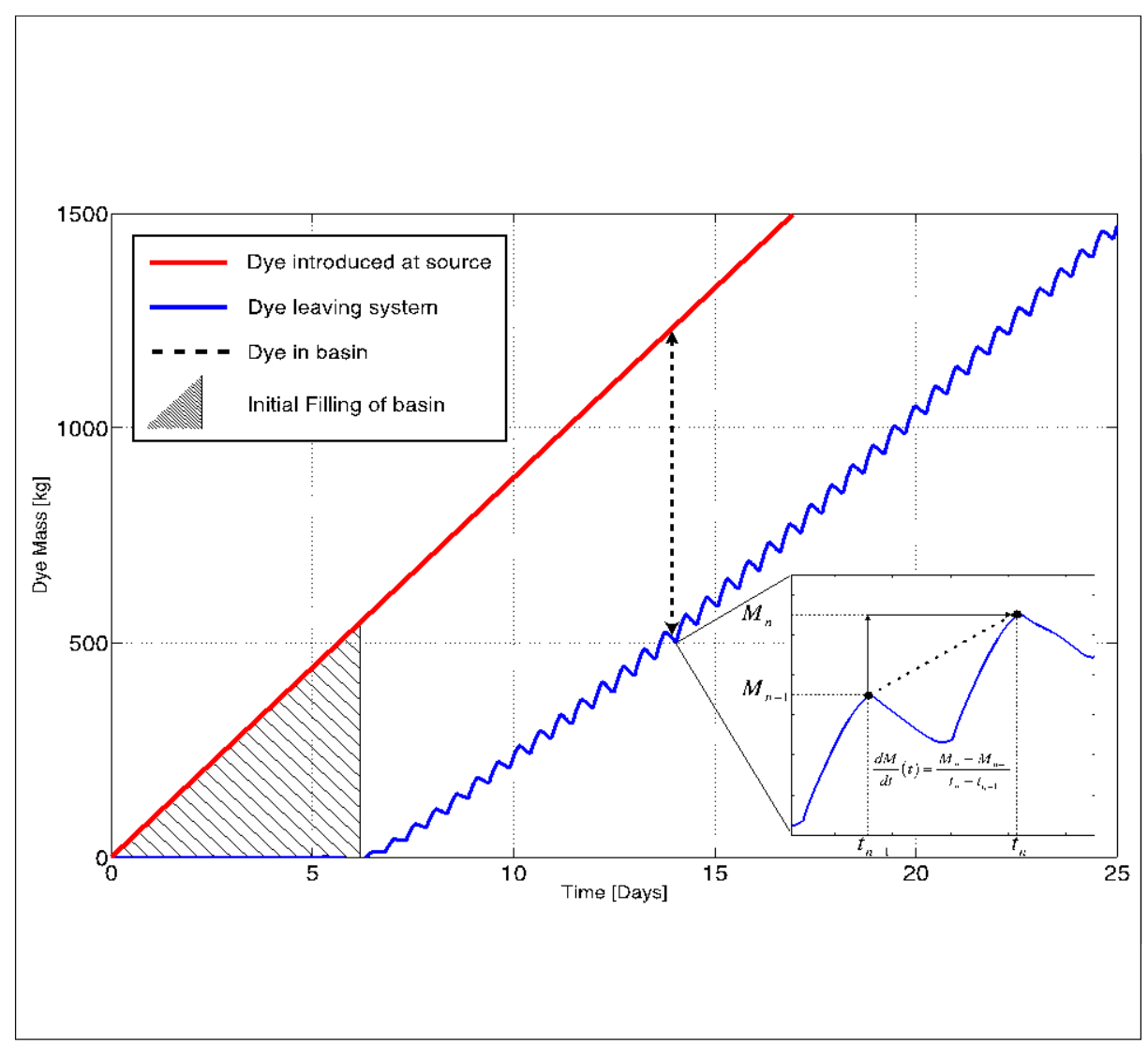

Figure A1: Using a cumulative advection of dye curve, the tidally-averaged mass of dye in the lagoon can be calculated once the system reaches equilibrium. 


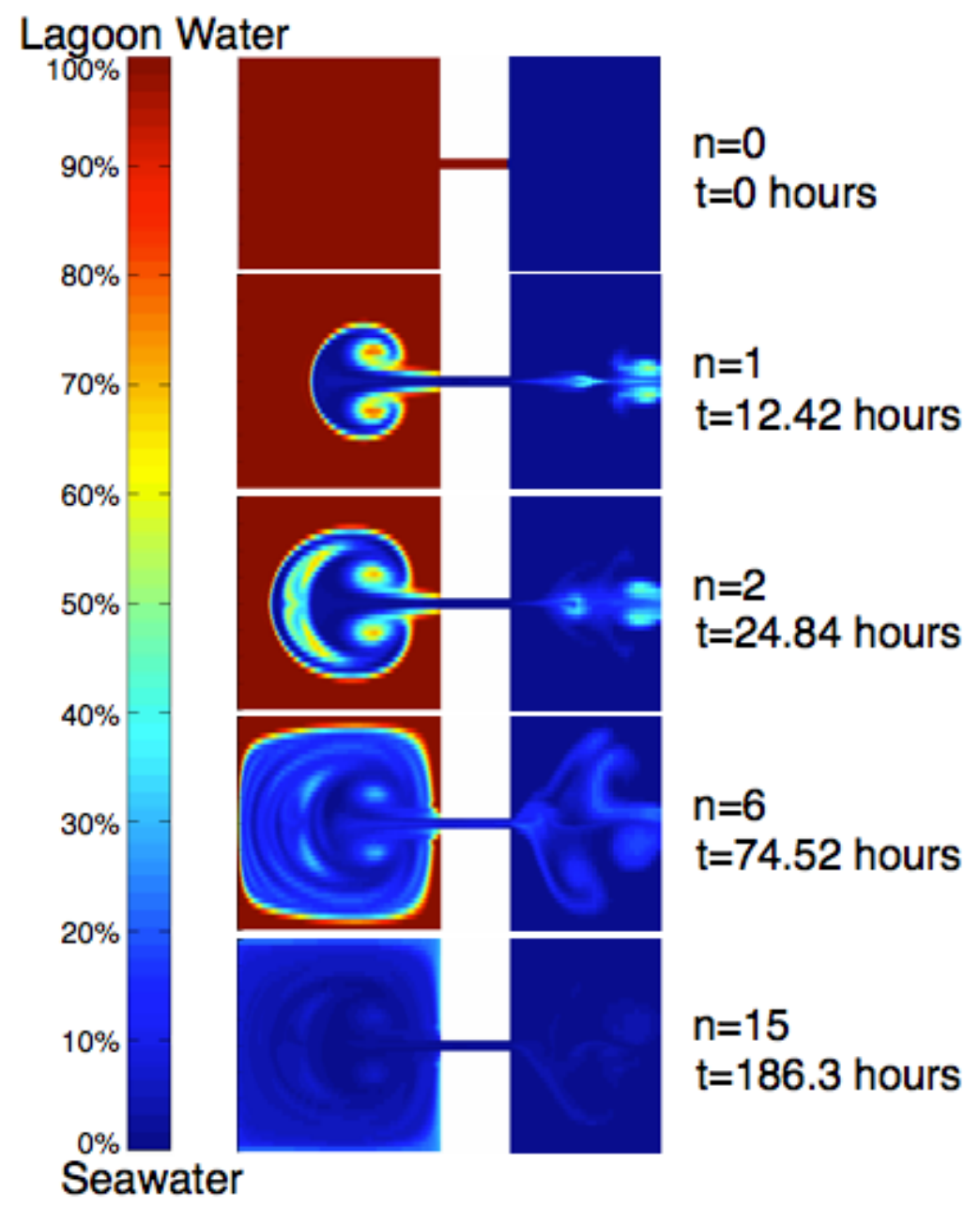

Figure A2: Delft3D output showing the distribution of lagoon water (red) and seawater (blue) after multiple tidal cycles of the baseline scenario. 

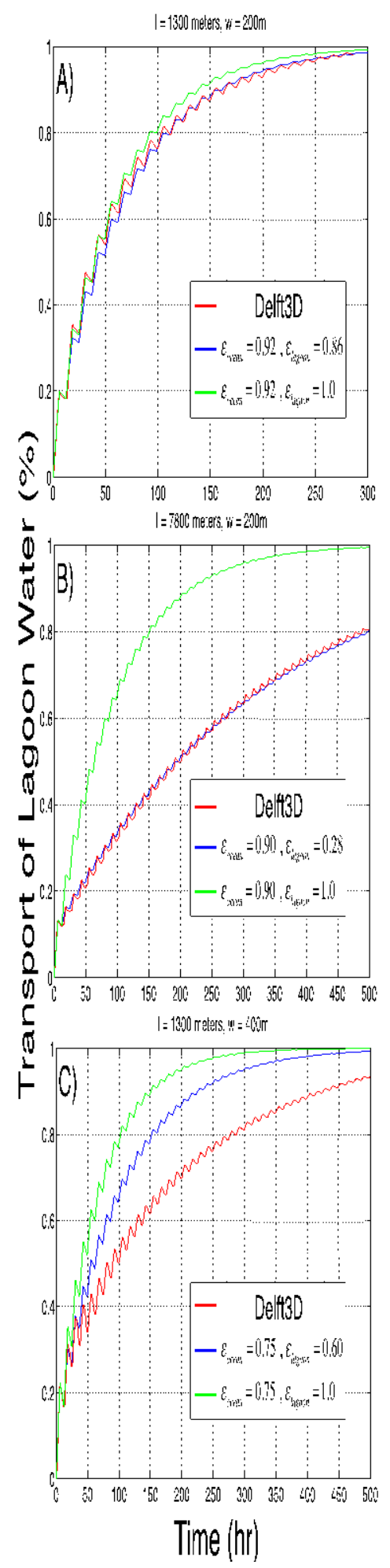

Figure A3: The cumulative transport of lagoon water out of a basin with varying inlet geometries using Delft3D (red), the simple transport model that includes both tidal exchange fractions (blue), and the simple transport model that assumes complete mixing in the lagoon (green). 

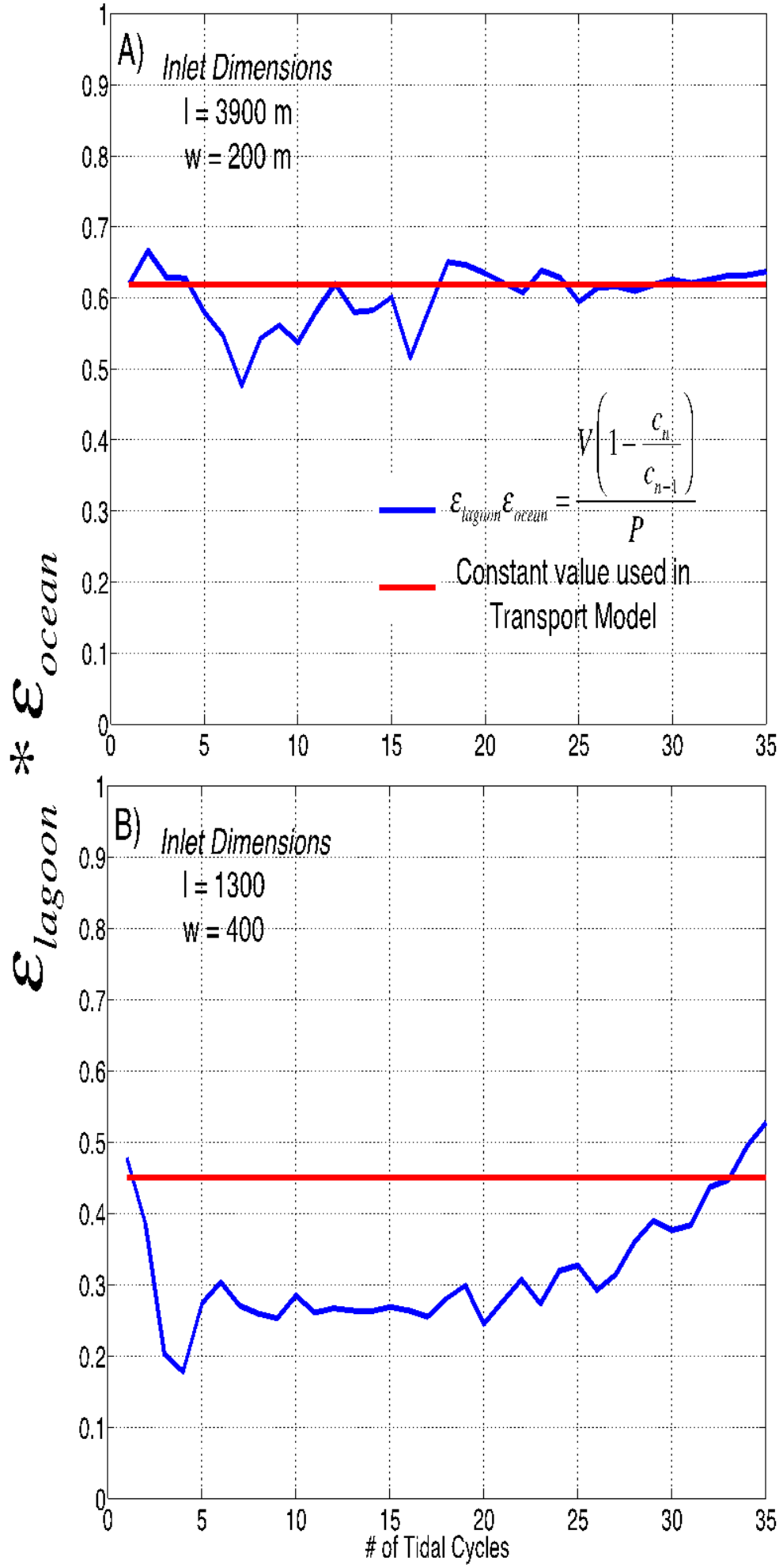

Figure A4: The product of the tidal exchange fractions is relatively constant for narrow inlets $(A)$ and less for wider inlets (B). The drop in exchange in wider inlets is attributed to an inlets inability to transport lagoon waters away from the flood withdrawal zone over multiple tidal cycles. 